\title{
Pemanfaatan Program Netop School Untuk Meningkatkan Hasil Belajar Siswa Pada Mata Pelajaran Seni Desain Grafis Di SMP Islam Al Azhar 22 Sentra Primer Jakarta
}

\author{
Taufan Himawan $^{1}$, Ivan Hanafi², Yuliatri Sastrawijaya ${ }^{3}$ \\ ${ }^{1}$ Pendidikan Teknik Informatika dan Komputer, Teknik Elektro, FT - UNJ \\ ${ }^{2,3}$ Pendidikan Teknik Informatika dan Komputer, Teknik Elektro, FT - UNJ \\ ${ }^{1}$ topenghimeng@gmail.com, ${ }^{2}$ ihanafi@unj.ac.id, ${ }^{3}$ yuliatri@unj.ac.id
}

\begin{abstract}
Abstrak
Penelitian ini dilatarbelakangi oleh rendahnya hasil belajar seni desain grafis, khususnya pada aspek keterampilan menggambar menggunakan perangkat lunak pengolah grafis yaitu Corel Draw 11. Penelitian ini bertujuan untuk meningkatkan hasil belajar seni desain grafis dengan memanfaatkan program Netop School sebagai strategi pembelajaran terutama pada pokok bahasan menggambar menggunakan software pengolah grafis yaitu Corel Draw 11. Jenis penelitian ini adalah Penelitian Tindakan Kelas dengan tiga siklus yang terdiri dari dua kali pertemuan dalam satu siklus, setiap siklus terdiri dari: perencanaan, pelaksanaan, pengamatan dan refleksi. Teknik dan alat pengumpulan data pada penelitian ini menggunakan teknik analisis deskriptif terhadap data berupa dokumen hasil pekerjaan siswa, daftar nilai dan lembar observasi. Penelitian ini dilaksanakan di SMP Islam Al Azhar 22 Sentra Primer Jakarta. Subjek yang menjadi penelitian ini adalah siswa kelas VII A dengan jumlah 36 siswa. Hasil penelitian menunjukkan bahwa dengan memanfaatkan program Netop School terjadi peningkatan hasil belajar, yaitu jumlah siswa yang tuntas mencapai KKM pada siklus I sebanyak 24 orang atau 67\%, siklus II yang sudah tuntas dan mencapai KKM sebanyak 31 orang atau 86\% dan pada siklus III sebanyak 36 telah mencapai KKM 100\%. Dengan demikian dapat disimpulkan bahwa strategi program Netop School dapat meningkatkan hasil belajar Seni Desain Grafis.
\end{abstract}

Kata kunci : Program Netop School, hasil belajar, seni desain grafis

\section{Pendahuluan}

Mata pelajaran Seni Desain Drafis adalah salah satu mata pelajaran yang mendukung kemampuan siswa untuk menghadapi perkembangan teknologi saat ini. Di SMP Islam Al Azhar 22 Sentra Primer Jakarta Timur mata pelajaran Seni Desain Grafis sangat penting karena perkembangan jaman dan teknologi diharapkan dapat mengatasi masalahmasalah yang terkait dengan teknologi informasi dan komunikasi. Untuk itu setiap proses dalam kegiatan belajar yang dirancang dan diselenggarakan oleh lembaga pendidikan (sekolah) berorientasi pada pencapaian tujuan pendidikan.

Kemajuan sekarang telah memberi kemudahankemudahan dalam berbagai hal, salah satunya adalah berkaitan dengan pengolahan gambar. Pengolahan gambar baik berupa pembuatan gambar, pengeditan gambar dan penyelesaian atau finishing gambar dapat dengan mudah dikerjakan dengan munggunakan piranti elektronika yaitu komputer. Saat ini desain grafis banyak dibutuhkan untuk berbagai kepentingan. Seperti pembuatan logo pada perusahaan-perusahaan, pengeditan gambar, foto, video, maupun yang digunakan sebagai media pembelajaran di kelas untuk peserta didik yang akan digunakan untuk pengembangannya di masa yang akan datang.

Mata pelajaran Seni Desain Grafis di SMP Islam Al Azhar 22 Sentra Primer Jakarta Timur merupakan mata pelajaran Seni Lukis yang dimodifikasi ke dalam bentuk digital menggunakan komputer. Saat ini terdapat beberapa aplikasi khusus untuk desain grafis yang banyak dijumpai salah satunya adalah Corel Draw. Adapun proses pembelajaran Seni Desain Grafis dilakukan oleh guru di laboratorium komputer.

Pada pembelajaran Seni Desain Grafis guru menjelaskan pengertian Corel Draw dan fungsinya 
termasuk beberapa tool pada toolbox untuk membuat contoh-contoh objek grafis kemudian dipahami dan dipraktikkan oleh siswa. Namun terdapat beberapa siswa yang kurang serius dan tidak fokus karena siswa lebih memilih untuk membuka program lain selain aplikasi Corel Draw dan banyak pula yang lebih memilih untuk bermain game, mendengarkan music/video yang tidak semestinya, browsing website yang tidak tepat dan banyak hal lainnya yang membuat pembelajaran tidak efektif sehingga hasil belajar siswa menurun dan siswa belum mengetahui fungsi dari tools yang ada pada Corel Draw.

Sementara itu dari pihak guru strategi dan model pembelajaran yang digunakan juga sangat mempengaruhi kualitas pembelajaran. Siswa banyak yang tidak memperhatikan guru, tidak merespon stimulasi yang diberikan oleh guru saat kegiatan pembelajaran berlangsung. Karena model pembelajaran yang dipakai guru dalam kegiatan pembelajaran tidak bervariasi, monoton dan membosankan. Metode pembelajarannya hanya ceramah, mendemonstrasikan objek-objek desain grafis, strategi pembelajaran tidak berpusat pada siswa sehingga minat belajar siswa menurun.

Hasil belajar nilai akhir yang meliputi ranah kognitif, afektif, psikomotorik dan proyek siswa kelas VII A pada semester ganjil tahun pelajaran 2014/2015 SMP Islam Al Azhar 22 Sentra Primer mata pelajaran Seni Desain Grafis yaitu hanya 20 siswa dari 36 siswa yang mencapai Kriteria Ketuntasan Minimal (KKM) atau 56\%, hal itu berarti 16 siswa atau 44\% belum mencapai KKM, di mana KKM yang ditetapkan adalah 80 dari skala 100. Oleh karena itu diperlukan adanya suatu tindakan pembelajaran yang dapat meningkatkan hasil belajar siswa.

Saat ini berkembang metode pembelajaran multimedia interaktif yang mampu membantu meningkatkan pemahaman siswa terhadap suatu materi. Siswa dapat mengexplorasi pengetahuan dengan mempelajari langsung dari sumber-sumber yang lain, salah satunya dengan menggunakan komputer yang di isi dengan materi pembelajaran multimedia interaktif dan terhubung dengan jaringan. Sebuah laboratorium komputer bisa difungsikan sebagai pusat belajar mandiri siswa, siswa dapat mengexplorasi segala hal yang ada di ruang tersebut, di mana didalamnya sudah memiliki fasilitas-fasilitas antara lain seperangkat komputer multimedia, materi pembelajaran interaktif, multimedia pembelajaran, program kontrol aktivitas siswa dan semua hal yang bisa mendukung siswa untuk menambah ilmu.
Belajar adalah suatu proses yang kompleks yang terjadi pada diri setiap orang dan berlangsung sepanjang hidupnya (life long education). Proses belajar dapat terjadi kapan saja dan di mana saja terlepas dari ada yang mengajar atau tidak. Proses belajar terjadi karena adanya interaksi individu dengan lingkungannya. Salah satu pertanda bahwa seseorang telah belajar adalah adanya perubahan dalam dirinya. Perubahan yang dimaksud adalah perubahan yang bersifat pengetahuan (kognitif) dan keterampilan (psikomotorik) maupun yang menyangkut nilai dan sikap (afektif). ${ }^{1}$

\section{Pembelajaran}

Pembelajaran merupakan terjemahan dari kata "instruction" yang dalam bahasa yunani disebut instructus atau "intruere" yang berarti menyampaikan pikiran, dengan demikian arti instruksional adalah menyampaikan pikiran atau ide yang telah diolah secara bermakna melalui pembelajaran. Pengertian ini lebih mengarah kepada guru sebagai pelaku perubahan. ${ }^{2}$

\section{Hasil Belajar}

Hasil belajar adalah kemampuan yang diperoleh anak setelah melalui kegiatan belajar. Dalam kegiatan pembelajaran atau kegiatan instruksional, biasanya guru menetapkan tujuan belajar. Siswa yang berhasil dalam belajar adalah yang berhasil mencapai tujuan-tujuan pembelajaran atau tujuan instruksional. Ada tiga ranah (domain) hasil belajar, yaitu kognitif, afektif dan psikomotorik. Hasil belajar merupakan keluaran (outputs) dari suatu sistem pemrosesan masukan (input). Masukan dari sistem tersebut berupa bermacam-macam informasi sedangkan keluarannya adalah perbuatan atau kinerja (performance). ${ }^{3}$

\section{Strategi Pembelajaran}

Strategi pembelajaran merupakan cara-cara yang dipilih untuk menyampaikan metode pembelajaran dalam lingkungan pembelajaran tertentu. Selanjutnya dijabarkan oleh mereka bahwa strategi pembelajaran dimaksud meliputi sifat lingkup dan urutan kegiatan pembelajaran yang dapat memberikan pengalaman belajar peserta didik. $^{4}$

\section{Pemanfaatan Program Netop School Sebagai Strategi Pembelajaran}

1 Winarso dkk, Teknik Evaluasi Multimedia Pembelajaran, (Malang: Genius Prima Media, 2009), hal. 1.

${ }^{2}$ Bambang Warsita, op.cit., hal. 265.

Asep Jihad \& Abdul Haris, Evaluasi Pembelajaran, (Yogyakarta: Multi Pressindo, 2012), hal. 14.

${ }^{4}$ Hamzah B. Uno, Model Pembelajaran, (Jakarta: Bumi Aksara, 2007), hal. 1.

\section{Dasar Teori Belajar}


Netop School adalah suatu program yang khusus diciptakan untuk membantu dalam proses pembelajaran dan pengawasan penggunaan komputer oleh siswa. Program Netop School saat ini sudah dalam versi 6.02 merupakan program yang dapat dijalankan dalam lingkungan LAN (Local Area Network). Program ini mempunyai 2 bagian yaitu program Netop School Teacher dan Netop School Student. Netop School Teacher merupakan program yang dijalankan pada komputer guru sebagai seorang administrator, sedangkan Netop Student merupakan program yang dijalankan pada komputer siswa sebagai client. Dengan software ini guru dapat memonitor seluruh tampilan layar siswa atau melihat program apa saja yang dijalankan oleh siswa dan sebaliknya, guru dapat menampilkan apa yang ada di monitornya supaya terlihat di komputer siswa. Guru melalui Netop School Teacher dapat berkomunikasi secara tulisan maupun dengan audio video, selain itu guru dapat mematikan atau menghidupkan komputer siswa secara remote apabila siswa melakukan tindakan yang tidak berkenan. ${ }^{5}$

\section{Jaringan Komputer}

Jaringan komputer (Computer Network) yang disebut secara singkat dengan jaringan adalah kumpulan komputer dan alat-alat lain yang saling dihubungkan bersama menggunakan media komunikasi tertentu. Informasi yang melintas sepanjang media komunikasi, memungkinkan pengguna jaringan untuk saling bertukar data atau menggunakan perangkat lunak maupun perangkat keras secara berbagi. Masing-masing komputer atau alat-alat lain yang dihubungkan pada jaringan adalah node.Jaringan dapat terdiri dari puluhan, ratusan atau bahkan ribuan node. Komputer dalam jaringan dapat saling berhubungan melalui kabel, jaringan telepon, gelombang radio, satelit ataupun sinar infra merah. Ada beberapa jenis tipe jaringan dalam hubungannya dengan luas area yang dicakup salah satunya adalah LAN (Local Area Network). LAN adalah suatu jaringan yang terbatas pada daerah yang relatif kecil. LAN biasanya terbatas pada daerah geografi tertentu, seperti laboratorium, sekolah, kantor atau gedung. ${ }^{6}$

\section{Corel Draw}

\footnotetext{
5 Tribudiyono, Instalasi Jaringan Lokal Area Network Dengan Memanfaatkan Program Netop School Sebagai Remote Akses di Laboratorium Komputer KKPI SMK Veteran 1 Sukoharjo, Vol. 2 No.1-Maret 2013, ISSN: 2302-1136, seruniid.unsa.ac.id, hal. 4.

6 Wagito, Jaringan Komputer Teori dan Impelementasi Berbasis Linux, (Yogyakarta: Gava Media, 2005), hal. 9.
}

Corel Draw adalah program desain grafis yang sangat terkenal dengan kualitas tinggi dan profesional. Program Corel Draw merupakan salah satu produk keluaran Corel Corporation di Kanada. Dengan Corel Draw, kita dapat mendesain grafis pengolah gambar vektor, seperti desain aneka brosur, poster, logo, dan produk-produk grafis lainnya. Kepopuleran program Corel Draw semakin hari semakin meningkat mengingat program tersebut banyak digunakan di berbagai kalangan seperti wartawan, penerbit,percetakan, industri periklanan, cetak foto, dan cetak sablon. Program aplikasi Corel Draw dilengkapi dengan fungsi (utility) yang lengkap dan canggih namun mudah digunakan serta dapat mengeluarkan hasil yang maksimal. ${ }^{7}$

\section{Metodologi \\ Penelitian Tindakan Kelas}

Pendekatan penelitian yang digunakan dalam penelitian ini adalah Penelitian Tindakan Kelas (PTK).

PTK merupakan bagian dari penelitian tindakan. Ciri khusus dari PTK adalah tindakan (action) yang nyata. Tindakan itu ditujukan untuk memecahkan permasalahan praktis. Tindakan tersebut merupakan sesuatu kegiatan yang sengaja dilakukan dengan tujuan tertentu. Pada penelitian tindakan, kegiatan tersebut dilakukan dalam rangkaian siklus kegiatan. ${ }^{8}$

Terdapat empat kegiatan yang ada pada setiap siklus, yaitu (a) perencanaan, (b) tindakan, (c) pengamatan, dan (d) refleksi yang dapat digambarkan sebagai berikut. ${ }^{9}$

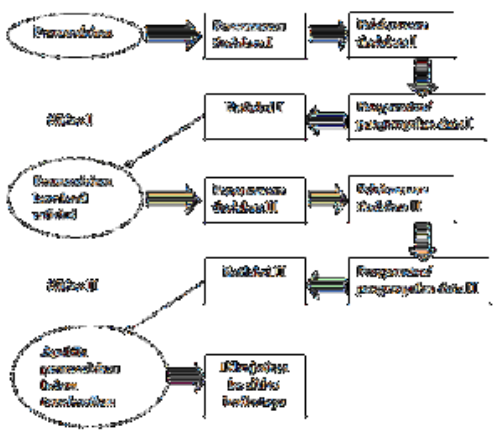

Gambar 3.1. Siklus Penelitian Tindakan Kelas

\section{Hasil dan Analisis}

Hasil penelitian dalam penelitian tindakan kelas ini secara garis besar dibagi menjadi dua, yaitu hasil pra tindakan dan hasil setelah dilakukan tindakan. Untuk lebih jelasnya deskripsi dan analisis mengenai penerapan pemanfaatan Netop School dan

7 Edi Purwanto, Cara Mudah Menggunakan Teknologi Informasi dan Komunikasi, (Jakarta: Widya Duta Grafika, 2010), hal. 9.

${ }^{8}$ Suharsimi Arikunto, Penelitian Tindakan Kelas, (Jakarta: Bumi Aksara, 2006), hal. 62.

${ }^{9}$ Suharsimi Arikunto, op.cit., hal. 74. 
kaitannya dengan peningkatan motivasi dan hasil belajar pada mata pelajaran Seni Desain Grafis Siswa Kelas VII A SMP Islam Al Azhar 22 Sentra Primer akan disajikan sebagai berikut.

\section{Hasil Penelitian Pra Siklus}

Tabel. 4.1. Rekapitulasi Hasil Belajar Pra Siklus

\begin{tabular}{|c|c|c|c|c|}
\hline \multirow[b]{2}{*}{ No } & \multirow[b]{2}{*}{ RESPONDEN } & \multirow[b]{2}{*}{$\mathbf{L} / \mathbf{P}$} & \multicolumn{2}{|r|}{ NILAI } \\
\hline & & & $\begin{array}{c}\text { PRA } \\
\text { SIKLUS }\end{array}$ & KETERANGAN \\
\hline 1 & Responden 1 & $P$ & 82 & Tuntas \\
\hline 2 & Responden 2 & $P$ & 57 & Belum Tuntas \\
\hline 3 & Responden 3 & $P$ & 71 & Belum Tuntas \\
\hline 4 & Responden 4 & $P$ & 85 & Tuntas \\
\hline 5 & Responden 5 & $\mathrm{P}$ & 80 & Tuntas \\
\hline 6 & Responden 6 & $\mathrm{~L}$ & 71 & Belum Tuntas \\
\hline 7 & Responden 7 & $\mathrm{~L}$ & 66 & Belum Tuntas \\
\hline 8 & Responden 8 & $\mathrm{~L}$ & 84 & Tuntas \\
\hline 9 & Responden 9 & $\mathrm{P}$ & 82 & Tuntas \\
\hline 10 & Responden 10 & $P$ & 66 & Belum Tuntas \\
\hline 11 & Responden 11 & $\mathrm{~L}$ & 80 & Tuntas \\
\hline 12 & Responden 12 & $\mathrm{~L}$ & 80 & Tuntas \\
\hline 13 & Responden 13 & $P$ & 65 & Belum Tuntas \\
\hline 14 & Responden 14 & $\mathrm{~L}$ & 86 & Tuntas \\
\hline 15 & Responden 15 & $P$ & 66 & Belum Tuntas \\
\hline 16 & Responden 16 & $\mathrm{~L}$ & 60 & Belum Tuntas \\
\hline 17 & Responden 17 & $\mathrm{~L}$ & 80 & Tuntas \\
\hline 18 & Responden 18 & $\mathrm{~L}$ & 82 & Tuntas \\
\hline 19 & Responden 19 & $\mathrm{~L}$ & 61 & Belum Tuntas \\
\hline 20 & Responden 20 & $\mathrm{~L}$ & 83 & Tuntas \\
\hline 21 & Responden 21 & $\mathrm{~L}$ & 80 & Tuntas \\
\hline 22 & Responden 22 & $\mathrm{~L}$ & 55 & Belum Tuntas \\
\hline 23 & Responden 23 & $\mathrm{~L}$ & 80 & Tuntas \\
\hline 24 & Responden 24 & $\mathrm{~L}$ & 63 & Belum Tuntas \\
\hline 25 & Responden 25 & $\mathrm{~L}$ & 63 & Belum Tuntas \\
\hline 26 & Responden 26 & $\mathrm{~L}$ & 80 & Tuntas \\
\hline 27 & Responden 27 & $\mathrm{~L}$ & 82 & Tuntas \\
\hline 28 & Responden 28 & $\mathrm{P}$ & 80 & Tuntas \\
\hline 29 & Responden 29 & $\mathrm{~L}$ & 83 & Tuntas \\
\hline 30 & Responden 30 & $\mathrm{P}$ & 80 & Tuntas \\
\hline 31 & Responden 31 & $\mathrm{P}$ & 58 & Belum Tuntas \\
\hline 32 & Responden 32 & $P$ & 65 & Belum Tuntas \\
\hline 33 & Responden 33 & $\mathrm{P}$ & 84 & Tuntas \\
\hline 34 & Responden 34 & $\mathrm{~L}$ & 80 & Tuntas \\
\hline 35 & Responden 35 & $P$ & 54 & Belum Tuntas \\
\hline 36 & Responden 36 & $P$ & 57 & Belum Tuntas \\
\hline \multicolumn{2}{|c|}{ RATA-RATA } & & 73 & \\
\hline \multicolumn{2}{|c|}{ NILAI TERTINGGI } & & 86 & \\
\hline \multicolumn{2}{|c|}{ NILAI TERENDAH } & & 54 & \\
\hline \multicolumn{3}{|c|}{ PROSENTASE KETUNTASAN } & $56 \%$ & \\
\hline
\end{tabular}

Tabel 4.2. Rekapitulasi Hasil Pengamatan Sikap pada Siklus I

\begin{tabular}{clcccc}
\hline \multirow{2}{*}{ No. } & \multirow{2}{*}{ Aspek Yang Dinilai } & $\begin{array}{c}\text { Kuran } \\
\mathrm{g}(\mathrm{K})\end{array}$ & $\begin{array}{c}\text { Cukup } \\
(\mathrm{C})\end{array}$ & $\begin{array}{c}\text { Baik } \\
(\mathrm{B})\end{array}$ & $\begin{array}{c}\text { Sangat } \\
\text { Baik (SB) }\end{array}$ \\
\hline 1. & Keaktifan siswa & - & $31 \%$ & $61 \%$ & $8 \%$ \\
\hline 2. & Perhatian siswa & - & $14 \%$ & $61 \%$ & $25 \%$ \\
\hline 3. & Kedisiplinan siswa & - & $3 \%$ & $58 \%$ & $39 \%$ \\
\hline 4. & Kejujuran siswa & - & $17 \%$ & $50 \%$ & $33 \%$ \\
\hline
\end{tabular}

Selanjutnya untuk memperoleh gambaran tentang pengamatan sikap siswa pada siklus I, dapat dilihat dalam diagram batang berikut ini.

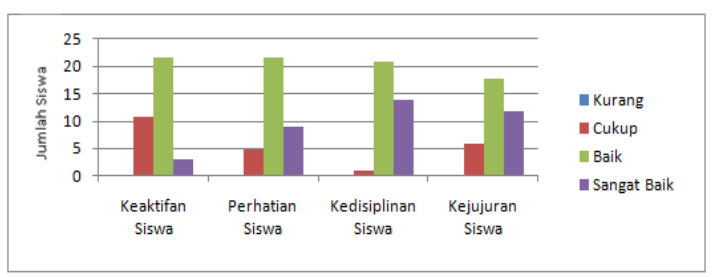

Gambar 4.1. Diagram Batang Hasil Pengamatan Sikap pada Siklus I

Selanjutnya jika dilihat dari persentase ketuntasan belajar maka dapat diterangkan melalui tabel berikut ini.

Tabel 4.3. Rekapitulasi Hasil Belajar Siklus I

\begin{tabular}{|c|c|c|c|c|}
\hline \multirow{2}{*}{ NO } & \multirow{2}{*}{ RESPONDEN } & \multirow{2}{*}{$\mathbf{L} / \mathbf{P}$} & \multicolumn{2}{|r|}{ NILAI } \\
\hline & & & SIKLUS I & KETERANGAN \\
\hline 1 & Responden 1 & $\bar{P}$ & 85 & Tuntas \\
\hline 2 & Responden 2 & $\mathrm{P}$ & 62 & Belum Tuntas \\
\hline 3 & Responden 3 & $P$ & 83 & Tuntas \\
\hline 4 & Responden 4 & $P$ & 87 & Tuntas \\
\hline 5 & Responden 5 & $\mathrm{P}$ & 85 & Tuntas \\
\hline 6 & Responden 6 & $\mathrm{~L}$ & 71 & Belum Tuntas \\
\hline 7 & Responden 7 & $\mathrm{~L}$ & 70 & Belum Tuntas \\
\hline 8 & Responden 8 & $\mathrm{~L}$ & 89 & Tuntas \\
\hline 9 & Responden 9 & $\mathrm{P}$ & 86 & Tuntas \\
\hline 10 & Responden 10 & $P$ & 68 & Belum Tuntas \\
\hline 11 & Responden 11 & $\mathrm{~L}$ & 82 & Tuntas \\
\hline 12 & Responden 12 & $\mathrm{~L}$ & 83 & Tuntas \\
\hline 13 & Responden 13 & $P$ & 80 & Tuntas \\
\hline 14 & Responden 14 & $\mathrm{~L}$ & 85 & Tuntas \\
\hline 15 & Responden 15 & $P$ & 83 & Tuntas \\
\hline 16 & Responden 16 & $\mathrm{~L}$ & 69 & Belum Tuntas \\
\hline 17 & Responden 17 & $\mathrm{~L}$ & 82 & Tuntas \\
\hline 18 & Responden 18 & $\mathrm{~L}$ & 87 & Tuntas \\
\hline 19 & Responden 19 & $\mathrm{~L}$ & 62 & Belum Tuntas \\
\hline 20 & Responden 20 & $\mathrm{~L}$ & 82 & Tuntas \\
\hline 21 & Responden 21 & $\mathrm{~L}$ & 82 & Tuntas \\
\hline 22 & Responden 22 & $\mathrm{~L}$ & 70 & Belum Tuntas \\
\hline 23 & Responden 23 & $\mathrm{~L}$ & 85 & Tuntas \\
\hline 24 & Responden 24 & $\mathrm{~L}$ & 82 & Tuntas \\
\hline 25 & Responden 25 & $\mathrm{~L}$ & 67 & Belum Tuntas \\
\hline 26 & Responden 26 & $\mathrm{~L}$ & 86 & Tuntas \\
\hline 27 & Responden 27 & $\mathrm{~L}$ & 91 & Tuntas \\
\hline 28 & Responden 28 & $P$ & 80 & Tuntas \\
\hline 29 & Responden 29 & $\mathrm{~L}$ & 85 & Tuntas \\
\hline 30 & Responden 30 & $\mathrm{P}$ & 82 & Tuntas \\
\hline 31 & Responden 31 & $\mathrm{P}$ & 67 & Belum Tuntas \\
\hline 32 & Responden 32 & $P$ & 71 & Belum Tuntas \\
\hline 33 & Responden 33 & $\mathrm{P}$ & 80 & Tuntas \\
\hline 34 & Responden 34 & $\mathrm{~L}$ & 84 & Tuntas \\
\hline 35 & Responden 35 & $P$ & 71 & Belum Tuntas \\
\hline 36 & Responden 36 & $P$ & 74 & Belum Tuntas \\
\hline \multicolumn{2}{|c|}{$\begin{array}{l}\text { RATA-RATA } \\
\end{array}$} & & 79 & \\
\hline \multicolumn{2}{|c|}{ NILAI TERTINGGI } & & 91 & \\
\hline \multicolumn{2}{|c|}{ NILAI TERENDAH } & & 62 & \\
\hline \multicolumn{3}{|c|}{ PROSENTASE KETUNTASAN } & $67 \%$ & \\
\hline
\end{tabular}

Selanjutnya diagram batang ketuntasan hasil belajar siklus I disajikan pada gambar berikut ini.

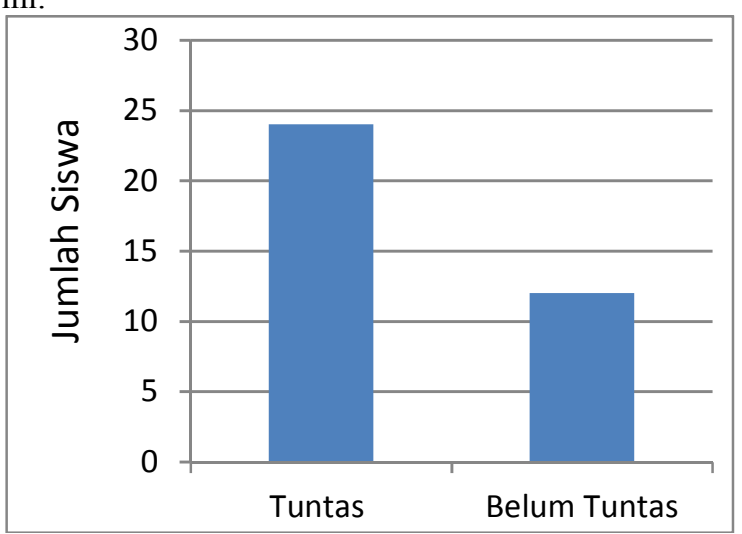


Gambar 4.2. Diagram Batang Ketuntasan Hasil Belajar Siklus I

Siklus II

Tabel 4.4. Rekapitulasi Hasil Pengamatan Sikap pada Siklus II

\begin{tabular}{cccccc}
\hline \multirow{2}{*}{ No. } & $\begin{array}{c}\text { Aspek Yang } \\
\text { Dinilai }\end{array}$ & $\begin{array}{c}\text { Kurang } \\
(\mathrm{K})\end{array}$ & $\begin{array}{c}\text { Cukup } \\
(\mathrm{C})\end{array}$ & $\begin{array}{c}\text { Baik } \\
(\mathrm{B})\end{array}$ & $\begin{array}{c}\text { Sangat Baik } \\
(\mathrm{SB})\end{array}$ \\
\hline 1. & Keaktifan siswa & - & $3 \%$ & $67 \%$ & $30 \%$ \\
\hline 2. & Perhatian siswa & - & $3 \%$ & $69 \%$ & $28 \%$ \\
\hline 3. & Kedisiplinan siswa & - & - & $56 \%$ & $44 \%$ \\
\hline 4. & Kejujuran siswa & - & $14 \%$ & $67 \%$ & $19 \%$ \\
\hline
\end{tabular}

Selanjutnya untuk memperoleh gambaran tentang pengamatan sikap siswa pada siklus II, dapat dilihat dalam diagram batang berikut ini.

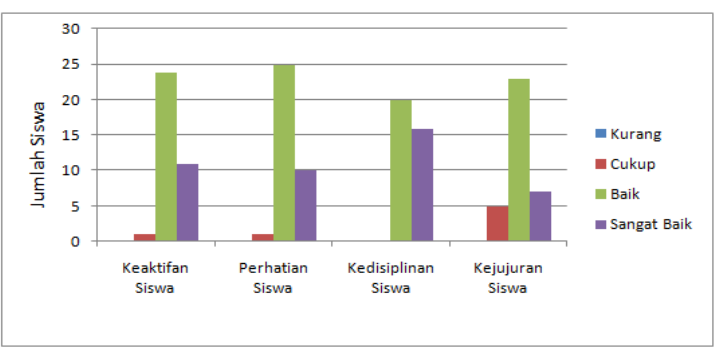

Gambar 4.3. Diagram Batang Hasil Pengamatan Sikap pada Siklus II

Selanjutnya jika dilihat dari persentase ketuntasan belajar maka dapat diterangkan melalui tabel berikut ini.

Tabel 4.5. Rekapitulasi Hasil Belajar Siklus II

\begin{tabular}{lllll}
\hline NO & RESPONDEN & L/P & \multicolumn{2}{l}{ NILAI } \\
\cline { 4 - 5 } & & SIKLUS & KETERANGAN \\
\hline 1 & Responden 1 & P & 82 & Tuntas \\
\hline 2 & Responden 2 & P & $\mathbf{7 0}$ & Belum Tuntas \\
\hline 3 & Responden 3 & P & 83 & Tuntas \\
\hline 4 & Responden 4 & P & 82 & Tuntas \\
\hline 5 & Responden 5 & P & 84 & Tuntas \\
\hline 6 & Responden 6 & L & 80 & Tuntas \\
\hline 7 & Responden 7 & L & 80 & Tuntas \\
\hline 8 & Responden 8 & L & 86 & Tuntas \\
\hline 9 & Responden 9 & P & 83 & Tuntas \\
\hline 10 & Responden 10 & P & 80 & Tuntas \\
\hline 11 & Responden 11 & L & 83 & Tuntas \\
\hline 12 & Responden 12 & L & 83 & Tuntas \\
\hline 13 & Responden 13 & P & 80 & Tuntas \\
\hline 14 & Responden 14 & L & 92 & Tuntas \\
\hline 15 & Responden 15 & P & 83 & Tuntas \\
\hline 16 & Responden 16 & L & 82 & Tuntas \\
\hline 17 & Responden 17 & L & 80 & Tuntas \\
\hline 18 & Responden 18 & L & 84 & Tuntas \\
\hline 19 & Responden 19 & L & 80 & Tuntas \\
\hline 20 & Responden 20 & L & 82 & Tuntas \\
\hline 21 & Responden 21 & L & 84 & Tuntas \\
\hline 22 & Responden 22 & L & $\mathbf{7 2}$ & Belum Tuntas \\
\hline 23 & Responden 23 & L & 83 & Tuntas \\
\hline 24 & Responden 24 & L & 81 & Tuntas \\
\hline 25 & Responden 25 & L & $\mathbf{7 2}$ & Belum Tuntas \\
\hline 26 & Responden 26 & L & 85 & Tuntas \\
\hline 27 & Responden 27 & L & 87 & Tuntas \\
\hline 28 & Responden 28 & P & 81 & Tuntas \\
\hline 29 & Responden 29 & L & 83 & Tuntas \\
\hline 30 & Responden 30 & P & 83 & Tuntas \\
\hline 31 & Responden 31 & P & 81 & Tuntas \\
\hline 32 & Responden 32 & P & 80 & Tuntas \\
\hline 33 & Responden 33 & P & 82 & Tuntas \\
\hline 34 & Responden 34 & L & 89 & Tuntas \\
\hline & & & & \\
\hline 12 & & & \\
\hline
\end{tabular}

\begin{tabular}{ccccc}
\hline 35 & Responden 35 & $\mathrm{P}$ & $\mathbf{7 4}$ & Belum Tuntas \\
\hline 36 & Responden 36 & $\mathrm{P}$ & $\mathbf{7 6}$ & Belum Tuntas \\
\hline RATA-RATA & & 81 & \\
\hline NILAI TERTINGGI & 92 & \\
\hline NILAI TERENDAH & 70 & \\
\hline PROSENTASE KETUNTASAN & $86 \%$ &
\end{tabular}

Selanjutnya diagram batang ketuntasan hasil belajar siklus I disajikan pada gambar berikut ini.

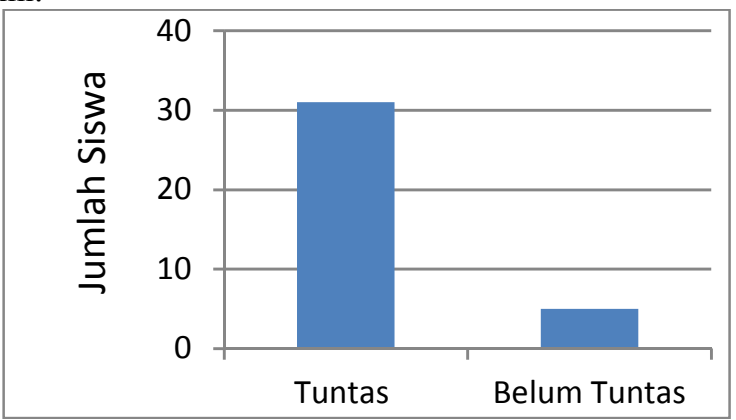

Gambar 4.4. Diagram Batang Ketuntasan Hasil Belajar Siklus II

Siklus III

Tabel 4.6. Rekapitulasi Hasil Pengamatan Sikap pada Siklus III

\begin{tabular}{cccccc}
\hline \multirow{2}{*}{ No. } & \multirow{2}{*}{$\begin{array}{c}\text { Aspek Yang } \\
\text { Dinilai }\end{array}$} & $\begin{array}{c}\text { Kurang } \\
(\mathrm{K})\end{array}$ & $\begin{array}{c}\text { Cukup } \\
(\mathrm{C})\end{array}$ & $\begin{array}{c}\text { Baik } \\
(\mathrm{B})\end{array}$ & $\begin{array}{c}\text { Sangat } \\
\text { Baik (SB) }\end{array}$ \\
\hline 1. & Keaktifan siswa & - & $3 \%$ & $47 \%$ & $50 \%$ \\
\hline 2. & Perhatian siswa & - & $3 \%$ & $56 \%$ & $42 \%$ \\
\hline 3. & Kedisiplinan siswa & - & - & $72 \%$ & $28 \%$ \\
\hline 4. & Kejujuran siswa & - & - & $75 \%$ & $25 \%$ \\
\hline
\end{tabular}

Selanjutnya untuk memperoleh gambaran tentang pengamatan sikap siswa pada siklus III, dapat dilihat dalam diagram batang berikut ini.

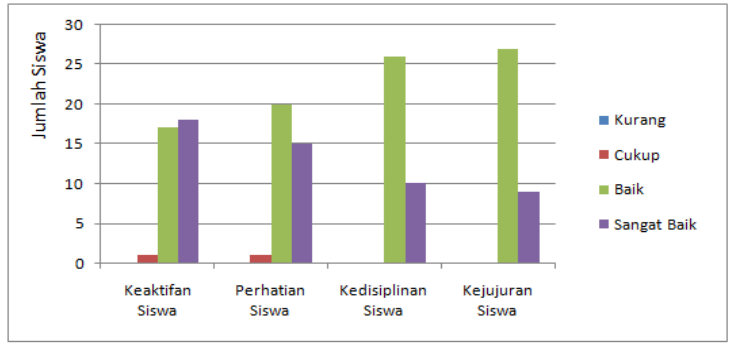

Gambar 4.3. Diagram Batang Hasil Pengamatan Sikap pada Siklus III

Selanjutnya jika dilihat dari persentase ketuntasan belajar maka dapat diterangkan melalui tabel berikut ini.

Tabel 4.7. Rekapitulasi Hasil Belajar Siklus III

\begin{tabular}{lllll}
\hline \multirow{2}{*}{ No. } & \multirow{2}{*}{ RESPONDEN } & L/P & \multicolumn{2}{c}{ NILAI } \\
\cline { 4 - 5 } & & SIKLUS & KETERANGAN \\
\hline 1 & Responden 1 & $\mathrm{P}$ & 85 & Tuntas \\
\hline 2 & Responden 2 & $\mathrm{P}$ & 84 & Tuntas \\
\hline 3 & Responden 3 & $\mathrm{P}$ & 82 & Tuntas \\
\hline 4 & Responden 4 & $\mathrm{P}$ & 82 & Tuntas \\
\hline 5 & Responden 5 & $\mathrm{P}$ & 85 & Tuntas \\
\hline 6 & Responden 6 & $\mathrm{~L}$ & 82 & Tuntas \\
\hline 7 & Responden 7 & $\mathrm{~L}$ & 82 & Tuntas \\
\hline 8 & Responden 8 & $\mathrm{~L}$ & 87 & Tuntas \\
\hline 9 & Responden 9 & $\mathrm{P}$ & 84 & Tuntas \\
\hline & & & & \\
\hline
\end{tabular}




\begin{tabular}{|c|c|c|c|c|}
\hline 10 & Responden 10 & $P$ & 82 & Tuntas \\
\hline 11 & Responden 11 & $\mathrm{~L}$ & 83 & Tuntas \\
\hline 12 & Responden 12 & $\mathrm{~L}$ & 82 & Tuntas \\
\hline 13 & Responden 13 & $P$ & 82 & Tuntas \\
\hline 14 & Responden 14 & $\mathrm{~L}$ & 92 & Tuntas \\
\hline 15 & Responden 15 & $\mathrm{P}$ & 82 & Tuntas \\
\hline 16 & Responden 16 & $\mathrm{~L}$ & 82 & Tuntas \\
\hline 17 & Responden 17 & $\mathrm{~L}$ & 82 & Tuntas \\
\hline 18 & Responden 18 & $\mathrm{~L}$ & 82 & Tuntas \\
\hline 19 & Responden 19 & L & 83 & Tuntas \\
\hline 20 & Responden 20 & $\mathrm{~L}$ & 82 & Tuntas \\
\hline 21 & Responden 21 & $\mathrm{~L}$ & 83 & Tuntas \\
\hline 22 & Responden 22 & $\mathrm{~L}$ & 82 & Tuntas \\
\hline 23 & Responden 23 & $\mathrm{~L}$ & 82 & Tuntas \\
\hline 24 & Responden 24 & $\mathrm{~L}$ & 82 & Tuntas \\
\hline 25 & Responden 25 & $\mathrm{~L}$ & 83 & Tuntas \\
\hline 26 & Responden 26 & $\mathrm{~L}$ & 85 & Tuntas \\
\hline 27 & Responden 27 & $\mathrm{~L}$ & 85 & Tuntas \\
\hline 28 & Responden 28 & $P$ & 84 & Tuntas \\
\hline 29 & Responden 29 & $\mathrm{~L}$ & 82 & Tuntas \\
\hline 30 & Responden 30 & $P$ & 84 & Tuntas \\
\hline 31 & Responden 31 & $P$ & 84 & Tuntas \\
\hline 32 & Responden 32 & $P$ & 84 & Tuntas \\
\hline 33 & Responden 33 & $P$ & 83 & Tuntas \\
\hline 34 & Responden 34 & $\mathrm{~L}$ & 92 & Tuntas \\
\hline 35 & Responden 35 & $P$ & 82 & Tuntas \\
\hline 36 & Responden 36 & $\mathrm{P}$ & 82 & Tuntas \\
\hline \multicolumn{2}{|c|}{ RATA-RATA } & & 83 & \\
\hline \multicolumn{2}{|c|}{ NILAI TERTINGGI } & & 92 & \\
\hline \multicolumn{2}{|c|}{ NILAI TERENDAH } & & 82 & \\
\hline \multicolumn{2}{|c|}{ PROSENTASE KETUNTASAN } & & $100 \%$ & \\
\hline
\end{tabular}

Selanjutnya jika digambarkan dalam bentuk diagram, maka kondisi hasil belajar siswa pada siklus III dapat dilihat dalam bentuk diagram batang berikut ini.

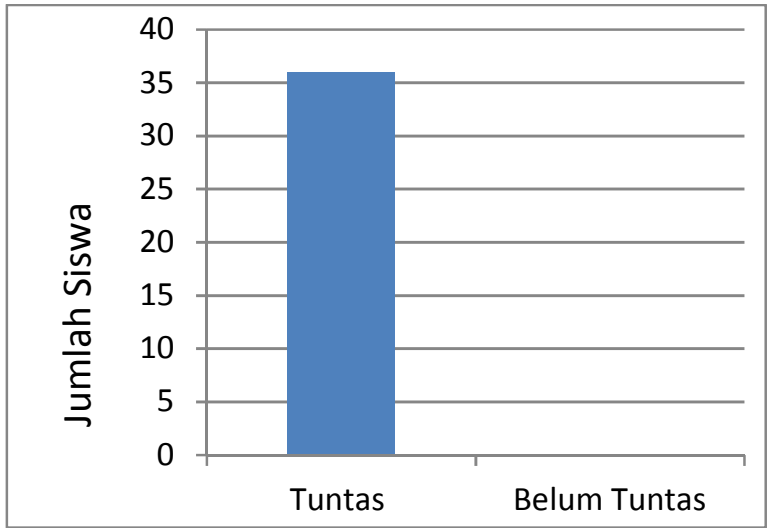

Gambar 4.6. Diagram Batang Ketuntasan Hasil Belajar Siklus III

Secara keseluruhan hasil penelitian yang telah dimulai dari tahap perencanaan, pelaksanaan, observasi dan kondisi pra siklus sampai tahapan refleksi yang terlaksana pada siklus I, siklus II, dan siklus III dapat dilihat pada tabel berikut.

Tabel 4.8. Rekapitulasi Hasil Belajar Pra Siklus s.d Siklus III

\begin{tabular}{clcccc}
\hline No. & Siklus & Tuntas & $\begin{array}{c}\text { Belum } \\
\text { Tuntas }\end{array}$ & $\begin{array}{c}\text { Nilai Rata- } \\
\text { rata }\end{array}$ & $\begin{array}{c}\text { Persentase } \\
\text { Ketuntasan }\end{array}$ \\
\hline 1. & Pra Siklus & 20 & 16 & 73 & $56 \%$ \\
\hline 2. & Siklus I & 24 & 12 & 79 & $67 \%$ \\
\hline 3. & Siklus II & 31 & 5 & 81 & $86 \%$ \\
\hline 4. & Siklus III & 36 & 0 & 83 & $100 \%$ \\
\hline
\end{tabular}

Selanjutnya agar lebih jelas mengenai peningkatan hasil belajar siswa dari pra siklus sampai dengan siklus III dapat dilihat pada diagram batang berikut.

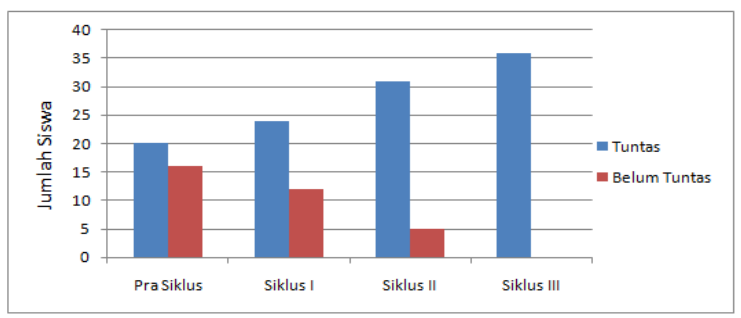

Gambar 4.7. Diagram Batang Ketuntasan Hasil Belajar dari Pra Siklus sampai dengan Siklus III

\section{Kesimpulan dan Saran Kesimpulan}

Pembelajaran dengan strategi pemanfaatan Netop School terbukti dapat meningkatkan hasil belajar Seni Desain Grafis yang ditunjukkan dengan adanya peningkatan persentase ketuntasan hasil belajar siswa kelas VII A SMP Islam Al Azhar 22 Sentra Primer. Adapun peningkatan hasil belajar dibuktikan dengan adanya peningkatan persentase ketuntasan belajar siswa sebagai berikut.

Sebelum diterapkannya strategi pemanfaatan Netop School, persentase hasil belajar yakni sebesar $56 \%$, kemudian setelah dilaksanakan pembelajaran siklus I dengan strategi Netop School ada peningkatan persentase menjadi 67\%. Pada siklus II meningkat lagi menjadi $86 \%$. Pada siklus III berhasil mencapai $100 \%$. Artinya hasil belajar siswa melalui penggunaan Netop School lebih baik karena dibuktikan dengan adanya peningkatan hasil belajar siswa dengan peningkatan ketuntasan belajar siswa dari pra tindakan sampai pada siklus III.

Setelah dilaksanakannya klinik atau bimbingan khusus terhadap siswa yang belum tuntas pada siklus I yaitu sebanyak 12 orang mengalami peningkatan aktivitas dan motivasi belajar, hal ini bisa dianalisis pada peningkatan hasil belajarnya telah mencapai ketuntasan yang ditentukan. Selanjutnya pada siklus II siswa yang belum tuntas sebanyak 5 orang setelah mengikuti bimbingan khusus atau klinik dengan baik mengalami peningkatan hasil belajar sesuai dengan kriteria yang telah ditentukan.

\section{Saran}

Berdasarkan kesimpulan yang disebutkan di atas maka penulis menyampaikan saran sebagai berikut.

1) Guru

a. Khususnya guru mata pelajaran Seni Desain Grafis, hendaknya menggunakan Netop School sebagai strategi pembelajaran agar siswa lebih aktif dalam mengikuti pelajaran.

b. Diharapkan ikut berperan aktif dalam meningkatkan pengetahuan dan kompetensi mengajar, sehingga kemampuan guru 
2) Siswa

dalam menggunakan variasi strategi pembelajaran dapat lebih baik.

Siswa hendaknya menumbuhkan kedisiplinan, motivasi dan mengikuti proses pembelajaran agar prestasi yang dicapai maksimal. Selain itu pembentukkan pengetahuan akan lebih bermakna apabila siswa berpartisipasi aktif di dalamya.

\subsection{Rekomendasi}

1. Salah satu wujud kepedulian guru terhadap kualitas hasil pembelajaran dituntut untuk melakukan inovasi-inovasi pendidikan dan pengajaran.

2. Untuk meningkatkan interaksi pembelajaran Seni Desain Grafis sebaiknya guru mengefektifkan strategi pemanfaatan menggunakan program Netop School dengan merumuskan permasalahan dan memberi kesempatan kepada siswa untuk berpikir.

3. Kepala sekolah untuk mempersiapkan guru agar lebih terampil dalam melakukan strategi pemanfaatan Netop School.

4. Kreatifitas siswa dalam proses pembelajaran ditunjang dengan keikutsertaan semua pihak khususnya dilingkungan pendidikan untuk memotivasinya.

\section{Daftar Pustaka:}

[FT] Fakultas Teknik. 2012. Buku Pedoman Skripsi/ Komprehensif/ Karya Inovatif (S1). Jakarta : Fakultas Teknik, Universitas Negeri Jakarta.

Arifin, Z. 2005. Langkah Mudah Membangun Jaringan Komputer. Yogyakarta: ANDI.

Arikunto, S. 2006. Penelitian Tindakan Kelas. Jakarta: Bumi Aksara.

Asep Jihad. Dan Abdul Haris. 2012. Evaluasi Pembelajaran. Yogyakarta: Multi Pressindo.

Fathurrahman, P. dan Sutikno, S. 2007. Strategi Belajar Mengajar. Bandung: Refika Aditama.

Hamdani. 2011. Strategi Belajar Mengajar. Bandung: Pustaka Setia.

Hendratman, H. 2014. Computer Graphic Design. Bandung: Informatika.

Jasmadi. 2004. 12 Langkah Menjadi Desainer Grafis Professional dengan CorelDRAW 12. Yogyakarta: ANDI.

Kusrianto, A. 2009. Berkarir di Dunia Grafis. Jakarta: Elex Media Komputindo.

Muslich, M. 2010. Penilaian Berbasis Kelas dan Kompetensi. Bandung: Refika Aditama.

Purwanto, E. 2010. Cara Mudah Menggunakan Teknologi Informasi dan Komunikasi. Jakarta: Widya Duta Grafika.

Purwanto. 2009. Evaluasi Hasil Belajar. Yogyakarta: Pustaka Pelajar.
Riyanto, Y. 2012. Paradigma Baru Pembelajaran. Jakarta: Kencana.

Rusman. 2012. Model-model Pembelajaran. Jakarta: Rajawali Pers.

Sardiman, 2011. Interkasi dan Motivasi Belajar Mengajar. Jakarta: Rajawali Pers.

Tribudiyono. 2013. Instalasi Jaringan Lokal Area Network Dengan Memanfaatkan Program Netop School Sebagai Remote Akses di Laboratorium Komputer KKPI SMK Veteran 1 Sukoharjo. Vol. 2:4 No.1. http://www.seruniid.unsa.ac.id $\quad[5 \quad$ Feb 2015]

Uno, H.B. 2007. Model Pembelajaran, Jakarta: Bumi Aksara.

Wagito. 2005. Jaringan Komputer Teori dan Impelementasi Berbasis Linux. Yogyakarta: Gava Media.

Warsita, B. 2008. Teknologi Pembelajaran. Jakarta: Rineka Cipta.

Winarso, dkk. 2009. Teknik Evaluasi Multimedia Pembelajaran. Malang: Genius Prima Media. 